\title{
The Ethno Botanical Uses of Medicinal Plants of Allai Valley, Western Himalaya Pakistan
}

\author{
Faizul Haq
}

Department of Botany, Hazara University, Mansehra. Pakistan

\begin{abstract}
This paper communicates the ethno botanical uses of medicinal plants of Allai valley. Floristically the area is placed in Western Himalayan Province located on the western edge of Himalayas, dominated by Sino-Japanese type of vegetation. Aims of the study were to document the medicinal plant resources and their use patterns. A total of 172 taxa were reported as locally used for various medicinal purposes. Majority of the recipes are prepared in the form of decoction from freshly collected plant parts. Mostly a single species were used and mainly taken orally. They used medicinal plants for asthma, cough, tonic, abdominal pain, and expectorant, anthelmintic, carminative, on boils, snakebites, jaundice, diarrhea and dysentery etc. Among 172 medicinal plants 24 were used for curing livestock. Field observation showed that vegetation of the area was generally threatened due to urbanization, deforestation, over grazing, habitat fragmentation, unscientific extraction of natural vegetation, introduction of the exotic taxa and habitat loss. Measures for the conservation of plant resources especially medicinal plants of Allai valley are urgently needed.
\end{abstract}

Keywords Western Himalayan, Medicinal Plants, Vegetation, Conservation, Allai Valley

\section{Introduction}

Primitive people were restricted to use plant resources for food, medicine and shelter. With the passage of time their dependency on plants increased both directly and indirectly[1]. Wild plants have always been used for their potential of human being[2]. After refining and addition the authentic knowledge of medicinal plants passed on from one generation to another[3]. With the passage of time wild plants were cleared from their original habitat to replace the desired cultivated crops on large scale. This practice has always been affected by the availability of plants in their natural habitat and the way these resources are used by the local people are imperative. In developing countries medicinal plants provide a real alternative for primary health care system[1].

According to an estimate between 35,000 and 70,000 plant species are used in folk medicine worldwide[4]. Products from hundreds of species are being collected from remote forests and meadows and traded to international markets and consumed[5]. About 70 to $80 \%$ of the world population use traditional medicine for curing their illness and ailments[6]. The percentage of people using traditional medicine decreased in developed countries[7] due to the availability of health facilities.

In Himalayan Mountains, certain areas are yet to be doc-

* Corresponding author:

faizulhaq80@yahoo.com (Faizul Haq)

Published online at http://journal.sapub.org/plant

Copyright $(\mathcal{C} 2012$ Scientific \& Academic Publishing. All Rights Reserved umented in the indigenous uses of medicinal plants[4]. One of such area is Allai valley western Himalaya. A detailed checklist of species diversity[8], traditional medicinal uses [1] and conservation study[9] of vascular flora of the adjacent Nandiar valley has been recently studied.

Present study was there-fore carried out to document the traditional knowledge of medicinal plants of Allai valley and provide scientific basis for further research.

\section{Objectives of the study were:}

(i) To explore and document the medicinal plants resources of Allai valley.

(ii) To collect information regarding to the plant uses, rate of consumption and rate of availability of medicinal plants.

(iii) To recommend ways for sustainable utilization of the local resources and to provide basis for further research.

\section{The Study Area}

The Allai Valley is located in the Western Himalayan Pakistan between $34^{\circ} 44^{\circ}$ and $34^{\circ} 58^{\circ} \mathrm{N}$ and $72^{\circ} 54^{\prime}$ and $73^{\circ}$ $15^{\prime} \mathrm{E}$ with a total area of 56081 ha. The Allai Valley is bounded by Kohistan valley in the north, by vast pasture meadows of Chaur in the east, by the Nandiar valley in the south and by the river Indus in the west[10]. The Allai Valley is generally rough and mountainous having variable slopes from gentle to precipitous including agricultural, wasteland, forest and alpine pasture and ranges in altitude from $545 \mathrm{~m}$ at Thakot to $4690 \mathrm{~m}$ at Sukaisar above mean sea level (GPS reading). The width of Allai valley varies from 
$0.5 \mathrm{~km}$ to $5 \mathrm{~km}$ and is accessible from Besham via Kond Saiyidan and Thakot located on Karakoram Highway[11]. Allai Khuwarr the main stream of the area to which all the small streams from different sub valleys joins at different locations, runs from East to West and joins River Indus near Besham at Kond Saiyidan. The nullahs, which feed the main stream, are Jabbar, Gantar, Batila and Pashto Khuwarrs[10].

\section{Materials and Methods}

The study was focused on Allai valley. Field trips to various parts of the selected area were undertaken from 1st May, 2009 to 30th Sep, 2011 to collect the information and specimens. Fieldwork was carried out in order to explore medicinal plant diversity. Plant specimens were collected along with extensive field's notes including habit, habitat, life form, abundance, GPS value etc. For each plant, ethno botanical information was collected from people of different ages belonging to different sub localities. During the interviews, semi-structured questionnaire was developed as per modification from Lipp (1989) and Ali and Qaiser (2009)[12,4]. Field numbers were allotted to the specimens and field data. Scientific names, vernacular names, family and other relevant information were recorded properly. The specimens were identified through the flora of Paki$\operatorname{stan}[13-15]$.

\section{Results}

During present survey it was noted that various parts of 172 plant species belongs to 95 families are used for medicinal purpose. Among them fungi was represented by single-family Helvelaceae with one species, Pteridophytes by 3 families and 5 species, Gymnosperms by 3 families and 5 species and Angiosperms by 88 families and 161 species.

Due to over exploitation of certain plant species such as Acer caesium Betula utilis, Cornus macrophylla, Dioscorea deltoidea, Pistacea integerrima, Paeonia emodi, Cedrus deodara, Skimmia laureola, Taxus wallichiana, Aesculus indica, Rhododendron arboreum, Podophyllum emodi, Viola canescens and Morchilla sp. by the local people, a drastic decrease has been observed in the population of these taxa in the wild. Unsustainable means of collection and ignorance of the people are the main causes of depletion of their population in the wild. These taxa deserve special attention on urgent basis, as their populations have alarmingly decreased in the wild. Conservation measures should be adapted immediately to protect these taxa from becoming extinct.

Some of the medicinal plant species are used individually, while other is in mixtures. The recipes may be taken in the form of fresh plant material, powder, or in the form of Paste. The powder form may be taken in small quantity along with milk or water. The recipes are taken two to three times a day for 3 to 15 days depends on the nature and intensity of disease.

The medicinal flora of the study area is given below:

1. Botanical Name: Abies pindrow Royle.

Local name: Achal

Family: Pinaceae

Traditional uses: Decoction of the dried shoots and fresh leaves is used in cough, asthma and other chest infection.

2. Botanical Name: Acacia modesta Wall.

Local name: Palosa

Family: Mimosaceae

Traditional uses: Dried gum is crushed, mixed in flour, sugar is added and then it is roasted in ghee and given to pregnant and lactating women as tonic. This is usually. It is also used for backache and weakness.

3. Botanical Name: Achillea mellefolium Linn.

Local name: Qarqara and Dambrai.

Family: Asteraceae

Traditional uses: Whole plant is used as antipyretic, stimulant and tonic, diaphoretic and diuretic. Decoctions are used to treat inflammations, such as hemorrhoids, and headaches. Decoction of flowering tops is used in cold, influenza and allergic mucus problems. Flowers infusion used for upper respiratory phlegm and used externally as a wash for eczema. Fresh leaves are uses to clot nose bleeding.

4. Botanical Name: Achyranthus aspera Linn.

Local name: Geshay

Family: Amaranthaceae

Traditional uses: The leaves extract are used for all skin problem in combination with sesame oil. Seed powdered are used for strengthen and whiting of teeth. The smoke of root and seed are used to relive cough and asthma. The powder of whole plant when mixed with sugar are used for relive of phlegm, breathlessness, continued cough, heaving etc. the leaves are also used in fever, piles and dog biting. Root extract are used in anemia, improving digestive system and constipation.

5. Botanical name: Aconitum heterophyllum Wall.

Local name: Sarba Zaila

Family: Ranunculaceae

Traditional uses: The dried tuberous roots and rhizome are used along with mutton for enhancing growth and weight.

6. Botanical name: Aconitum chasmanthum Stapf ex Holmes

Local Name: Zahar mora

Family: Ranunculaceae

Traditional uses: About 200 gram of fresh rhizome is fried in synthetic ghee and used before going to bed for body tonic.

7. Botanical Name: Acorus calamus Linn.

Local name: Skhawaja

Family: Acoraceae

Traditional uses: The powder rhizome is used in diarrhea and dysentery. The rhizome is thought to be a powerful aphrodisiac, stimulant and mild tonic. Powder the dried root 
and put this up the nose to cure a runny nose. Roasted fruits are grinded and are used as expectorants. Juice of leaves and roots are used as anthelmintic. It has wonderfully tonic powers of stimulating and normalizing the appetite. An infusion of the root can bring about an abortion whilst chewing the root alleviates toothache.

8. Botanical Name: Adiantum capillus veneris Linn.

Local name: Babozea

Family: Adiantaceae

Traditional uses: The infusion of fronds is used as diuretic, expectorant, in coughs, headache and toothache. The entire plant is used for its cooling effects, for diabetes, in lowering blood pressure, and externally it is used for boils, eczema, and wounds.

9. Botanical Name: Adiantum incisum Forssk.

Local name: Babozea

Family: Adiantaceae

Traditional uses: Fronds are used for skin diseases, cough and cold.

10. Botanical Name: Adiantum venustum D. Don.

Local name: Babozea

Family: Adiantaceae

Traditional uses: The fronds are used as astringent, diuretic, expectorant and tonic. The plant is used in the treatment of headaches and scorpion stings. A paste made from rhizomes is used to treat cuts and wounds. The plant is also used in combination with other plant species as expectorant, hypothermic, diuretic and in stomachache.

11. Botanical Name: Aesculus indica (Wall. ex. Cambl.)

Hook.f

Local name: Joze and Banakor

Family: Hippocastinaceae

Traditional uses: Powered seeds are traditionally administered to livestock as anthelmintic. Powered seeds are also used for jaundice. Wood used for turned articles.

12. Botanical Name: Ajuga bracteosa Wall. ex Benth.

Local name: Yakhabooti

Family: Labiatae

Traditional uses: Its fresh leaves decoction is used for curing jaundice, hypertension and very effective in sore throat.

13. Botanical Name: Albezia lebbeck J. L. Stewart.

Local name: Srikh

Family: Mimosaceae

Traditional uses: Powdered bark is used in diarrhea and dysentery. The plant is also used as astringent, to treat boils, cough, to treat eye, flu, lung problems, tonic, and is used to treat abdominal tumors.

14. Botanical Name: Allium cepa $\mathrm{L}$.

Local name: Piaz

Family: Alliaceae

Traditional uses: The juice of fresh plant is mixed with honey and is used for treatment of flue, cholera and diabetes. The bulb is eaten and smelled along with sugar to avoid vomiting.

15. Botanical Name: Allium filidens Regel.

Local name: Oogakay
Family: Alliaceae

Traditional uses: Fresh leaves are bitter in taste and are eaten raw or cooked along with other pot herbs for gastrointestinal disorders especially stomachache.

16. Botanical Name: Allium sativum L.

Local name: Ooga

Family: Alliaceae

Traditional uses: The fruit is eaten with water at morning before breakfast, which reduces the high blood pressure. The fruit is ground and its juice is extracted and used for earache, reduction of high blood pressure and body pain.

17. Botanical Name: Amaranthus caudatus Linn.

Local name: Chaleray

Family: Amaranthaceae

Traditional uses: The decoction of shoots and leaves are used in cough and asthma, diuretic, sores, piles and other pulmonary diseases. The root is boiled with honey and is used as laxative.

18. Botanical Name: Amaranthus viridus Linn.

Local name: Ganhar

Family: Amaranthaceae

Traditional uses: It is eaten traditionally as a vegetable and the paste of leaves and roots are applied on boils and scorpion sting.

19. Botanical Name: Arisaema flavum (Forssk) Schott.

Local name: Marjarai

Family: Araceae

Traditional uses: Fruit is eaten without chewing in cough and cold.

20. Botanical Name: Artemisia spp.

Local name: Tarkha or Jau,

Family: Asteraceae

Traditional uses: The juice of leaves and inflorescence are used as anthelmintic.

21. Botanical Name: Asparagus officinalis Linn.

Local name: Tindoray

Family: Asparagaceae

Traditional use: Young shoots are fed to livestock for promoting lactation. It is also used as a diuretic and laxative.

22. Botanical Name: Berberis lycium Royle.

Local name: Kwaray

Family: Berberidaceae

Traditional uses: The powder bark of root is used as antiseptic, as remedy for swollen and sore eyes, broken bones, wounds, gonorrhea and curative piles. Leaves are given in jaundice. The plant is used for the treatment of internal injuries. An ointment made from root bark powder is mix with oil and applied on broken bones. The paste of powder bark is used in backache and as general body tonic.

23. Botanical Name: Bergenia ciliata Sternb.

Local name: Gut panra

Family: Saxifragaceae

Traditional uses: Juice or powder of the whole plant is used to treat urinary troubles. The juice of the leaves is used as drops to relieve earaches. The rhizome is used in powder or paste form in diarrhea, stomach and duodenal ulcers, as 
tonic, helpful in relieving backache and muscular disorders. The root juice is used to treat coughs and colds, hemorrhoids, asthma and urinary problems.

24. Botanical Name: Betula utilis D. Don.

Local name: Broj

Family: Betulaceae

Traditional uses: Birch bark soaked until moist in water, and then formed into a cast for a broken arm. Bark is used in various recipes and for amulet.

25. Botanical Name: Caesalpinia decapitala (Roth) Alston.

Local name: Jara

Family: Caesalpinaceae

Traditional uses: Decoction of young shoots is used as analgesic and antipyretic.

26. Botanical Name: Calotropis procera (Wild.) R. Br.

Local name: Spalmay

Family: Asclepiadaceae

Traditional uses: Leaves are applied as poultice on dog bitten wounds. An infusion of bark powder is used in the treatment and cure of leprosy. Bark and wood stimulate lactation in cattle. Roots are applied for snakebite.

\section{Botanical Name: Caltha alba}

Local name: Makan path

Family: Ranunculaceae

Traditional uses: The plant is used to stop pain and cramps, for menstrual disorders, bronchial inflammation, jaundice, and liver disorders. Flowering shoots is used as a laxative and diuretic. It is also used for cleaning skin lesions and sores.

28. Botanical Name: Cannabis sativa Linn.

Local name: Bhang

Family: Canabinaceae

Traditional uses: The decoction of flowering tops is used as sedative, anodyne and narcotic.

29. Botanical Name: Cedrella serrata Royle

Local name: Meem

Family: Meliaceae

Traditional uses: Whole plant is considered as poisonous. The leaf, stem and root bark is used for curing roundworms. Leaves decoction is excellent hair wash. The juice is administrated in diabetes and it also produces body coldness.

30. Botanical Name: Cedrus deodara Roxb. ex Lamb.

Local name: Ranzrah

Family: Pinaceae

Traditional uses: A decoction of the wood is used in the treatment of fevers, flatulence, pulmonary and urinary disorders, rheumatism, piles, kidney stones and diabetes. It has been used as an antidote to snake bites. Resin is used externally to treat skin diseases and injuries to joints. Leaves are used in the treatment of tuberculosis. The extract of the wood (Ranzrah) is administrated to the livestock as anthelmintic. It is a valuable timber, but a poor fuel, producing a lot of smoke when it burns.

31. Botanical Name: Celtis australis Linn.

Local name: Batkar

Family: Ulmaceae
Traditional uses: A decoction of both leaves and fruit is used in the treatment of amenorrhea, heavy menstrual and inter-menstrual bleeding, astringent, lenitive and stomachic and colic. The decoction is also used in the treatment of diarrhea, dysentery and peptic ulcers. Decoction from bark is administrated as anti-allergic.

32. Botanical Name: Cephalanthera longifolia (L) Fritsch.

Family: Orchidaceae

Traditional uses: The rhizome is considered as promoting lactation in livestock, and is given along with Maize flour.

33. Botanical Name: Chenopodium album Linn.

Local name: Bathu

Family: Chenopodiaceae

Traditional uses: This plant is said to be laxative, and uses in hepatic disorder and enlarge spleen. Whole plant is used in abdominal pains and as diuretic.

34. Botanical Name: Cichorium intybus Linn.

Local name: Kasni

Family: Asteraceae

Traditional uses: The whole plant is taken internally for loss of appetite, jaundice, gallstones, gout and rheumatism. The leaves are used as compresses to be applied externally to ease skin inflammations and swellings. The roots are washed, boiled and filtrate is kept for whole night in open sky and then used for abdominal pain.

35. Botanical Name: Cissampelos pareira Linn.

Local name: Gorisum

Family: Menispermaceae

Traditional Uses: It is mainly used for treating women's diseases as a cure for menstrual problems, hormonal imbalance, and to ease childbirth, postpartum pain, prevent miscarriage, and control uterine hemorrhages, hormonal acne and premenstrual syndrome. A decoction of the whole vine is taken by women for 2 months before and throughout pregnancy and again three months after delivery. The plant is also used in dysentery, piles, dropsy and to stop uterine haemorrhages. A decoction of the leaf and stem is used as an oral analgesic. The toasted seeds are brewed into a tea for treatment of internal haemorrhages and external bleeding. The leaves extract are administrated to livestock for diarrhea treatment.

36. Botanical Name: Clematis grata Wall.

Local name: Chinjanoly

Family: Ranunculaceae

Traditional uses: The shoots extracts is considered as antimycotic, applied to ring worm and baldness.

37. Botanical Name: Clematis montana Buch.

Local name: Chinjanoly

Family: Ranunculaceae

Traditional uses: The decoction of flowers is used in cough.

38. Botanical Name: Colchicum luteum Baker.

Local name: Suranjan

Family: Colchicaceae

Traditional uses: Fresh corm are mixed with eggs and fried in Ghee and given to aged people for curing joints pain. 
39. Botanical Name: Convolvulus arvensis Linn.

Local name: Ellay

Family: Convolvulaceae

Traditional uses: Tea made from leaves used as a wash on spider bites. Tea ingested to reduce profuse menstruation. Flower tea used to reduce fever and heal wounds. Roots have strong emetic effects. The roots are dried, powdered and used as purgative and is also used as diuretic. Whole plant is used as laxative.

40. Botanical Name: Corydalis stewartii Fedde.

Local name: Mamera

Family: Fumariaceae

Traditional uses: Floral drops are used for curing eye diseases.

41. Botanical Name: Cotinus coggyria Scop.

Local name: Chamyarlakhta or Miswakay

Family: Anacardiaceae

Traditional uses: Leaves are given to livestock against liver fluke. The yellow wood is used as febrifuge and for eye ailments.

42. Botanical Name: Cotoneaster microphylla Wall. ex Lindl.

Local name: Kharawa

Family: Rosaceae

Traditional uses: Fruit are used as expectorant and astringent, also effective in stomachache.

43. Botanical Name: Cotoneaster nummalaria Fish.

Local name: Mamana

Family: Rosaceae

Traditional uses: Fruit is edible and are used as astringent.

44. Botanical Name: Crataegus songarica C. Koch.

Local name: Batsinga

Family: Rosaceae

Traditional uses: Fruits are edible and considered as cardio tonic.

45. Botanical Name: Cuscuta gigantea Griff.

Local name: Akasbail

Family: Cuscutaceae

Traditional uses: Juice of plant is used as anti poisonous agent.

46. Botanical Name: Cynodon dactylon Linn.

Local name: Kabal

Family: Poaceae

Traditional uses: Cynodon dactylon have many medicinal properties including antimicrobial and antiviral properties, as well as treatment of urinary tract infections and dysentery. Fresh leaves are applied on cuts and bleeding wounds, bleeding piles, diuretic, antipyretic and diarrhea.

47. Botanical Name: Dalbergia sisso Roxb.

Local name: Shawa

Family: Papilionaceae

Traditional uses: Decoction of leaves is bitter, stimulant, used in gonorrhea. Root is astringent. Wood is used as alterative, useful in leprosy, boils and to stop vomiting.

48. Botanical Name: Daphne oloides Schreb.

Local name: Kutilal
Family: Thymalaceae

Traditional uses: Seeds and roots are used as anthalmintic. Fruit when directly eaten, cause nausea and vomiting. An infusion of the bark and leaves are used in the treatment of cutaneous affections.

49. Botanical Name: Daphne papyracea Wallich .ex Steud.

Local name: Jangali Kutilal

Family: Thymalaceae

Traditional uses: The juice of the leaves is used to kill the ectoparasites of livestock.

50. Botanical Name: Datura innoxia Miller.

Local name: Baturai

Family: Solanaceae

Traditional uses: Juice of the leaves is applied to the cutaneous affection of the head. Seeds are employed in fever.

51. Botanical Name: Datura stramonium Linn.

Local name: Datura

Family: Solanaceae

Traditional uses: All parts of Datura plants contain poison and may be fatal if ingested by humans or animals, including livestock and pets. Leaves are applied for the softening of the boils. Juice of the flower is used in earache.

52. Botanical Name: Debregessia salicifolia (D. Don.)

Rendle.

Local name: Ajlai

Family: Urticaceae

Traditional uses: Leaves are antiseptic also used for boils and other swellings.

53. Botanical Name: Delphinum vestitum Wall.ex Royle

Family: Ranunculaceae

Traditional uses: The juice of the flower is used as hair tonic.

54. Botanical Name: Descurainia sophia (L.) Webb. and Berth.

Local name: Khoob kalan

Family: Brassicaceae

Traditional uses: A poultice of the plant has been used to ease the pain of toothache. The juice of the plant is used in the treatment of chronic coughs, hoarseness and ulcerated sore throats. A strong decoction of the plant is used in the treatment of asthma. The flowers and the leaves are astringent. The seed is considered to be cardiotonic, demulcent, diuretic, expectorant, febrifuge, laxative, restorative and tonic. A poultice of the ground up seeds has been used on burns and sores.

55. Botanical Name: Desmodium elegans D. C.

Local name: Jamkat

Family: Papilionaceae

Traditional uses: The powder roots are used in chronic fever, cough, vomiting, asthma, and in snakebite. The juice of the root is used in the treatment of cholera.

56. Botanical Name: Deutzia staminea $\mathrm{R}$. Br .ex Wall.

Local name: Boritus

Family: Philadelphaceae

Traditional uses: Whole plant Remove the fleas from houses. 
57. Botanical Name: Dioscorea deltoidea Wall.

Local name: Kanis zela

Family: Dioscoreaceae

Traditional uses: The powder tuber is mixed with powdered root of Berberis lycium and is used for the treatment of jaundice. The juice is applied in hair to kill lice. Locally whole plant is crushed and used to kill fishes.

58. Botanical Name: Diospyros lotus Linn.

Local name: Tor Amlook

Family: Ebenaceae

Traditional uses: Fruits are carminative, purgative, anti febrile and causes flatulence. Local people boil the fruit in milk and take it for curing of constipation and dysentery.

59. Botanical Name: Dodonaea vescosa (L.) Jacq.

Local name: Ghwarasky

Family: Sapindaceae

Traditional uses: Stem and leaf infusions are used to treat sore throats and fever; root infusions to treat colds; the seeds mixed with honey is used to treat malaria, the stem are used as fumigants to treat rheumatism. The leaves are used to relive itching, fevers, swelling, aches and as antispasmodic. Leaves and roots are used as painkiller to soothe toothaches.

60. Botanical Name: Dryopteris jaxtapostia Chirst.

Local name: Kuanjay

Family: Dryopteridaceae

Traditional uses: Fronds enhance digestion.

61. Botanical Name: Elaegnus umbellata Thunb.

Local name: Ghanamranga

Family: Elagnaceae

Traditional uses: Flowers and seeds are stimulant and astringent. Seed oil is used in pulmonary infections.

62. Botanical Name: Equisetum arvense Linn.

Local name: Bandaky

Family: Equisetaceae

Traditional uses: The extract of the whole plant is used in jaundice. The herb is use as diuretic. Decoction of the fronds is used in rheumatism.

63. Botanical Name: Euphorbia indica Lam.

Local name: Jangali Spalmai

Family: Euphorbiaceae

Traditional uses: The milky juice is used against ringworm disease.

64. Botanical Name: Euphorbia wallichii Hook. f.

Local name: Hirvi

Family: Euphorbiaceae

Traditional uses: It is poisonous, highly laxative causes sever diarrhea and dysentery. Used in skin diseases.

65. Botanical Name: Ferula sp.

Local name: Hing

Family: Umbelliferae

Traditional uses: The decoction is used in cough, asthma, toothache, gastric problems and anti-constipation.

66. Botanical Name: Ficus carica Forsk.

Local name: Inzar

Family: Moraceae

Traditional uses: The roots are used in treatment of ring- worms. Its fruits have antipyretic, demulcent, purgative, aphrodisiac properties and have shown to be useful in inflammations and paralysis. The leaves are used in the treatment of jaundice. The latex is placed on the spot in which prickle has hidden; the prickle is easily drawn out from the outer skin of the body.

67. Botanical Name: Ficus palmata Forsk.

Local name: Inzar

Family: Moraceae

Traditional uses: The fruit is demulcent, emollient, laxative and poultice. It is used as a part of the diet in the treatment of constipation and diseases of the lungs and bladder. The latex of the plant is used to take out spines lodged deeply in the flesh.

68. Botanical Name: Ficus racemosa Linn.

Local name: Oormal

Family: Moraceae

Traditional uses: Leaves infusion is astringent. Fruits are used as carminative and astringent. The decoction of leaves is salutary in washing the wounds for better cleansing and healing. The decoction of bark and latex is used in diarrhea and dysentery. In diabetes, the ripe fruit, root and bark decoction is beneficial.

69. Botanical Name: Foeniculum vulgare Miller.

Local name: Saunf

Family: Apiaceae

Traditional uses: Fruits are carminative, purgative, and aromatic, used in stomach disorders and in fever. The decoction of fennel is employed as a carminative, relax the intestines and reduce bloating caused by digestive disorders. Fennel seeds are eaten raw or with sugar to improve eyesight. Extracts of fennel seed is used in the treatment of glaucoma in animal.

70. Botanical Name: Fragaria nubicola Lindl. ex Lac.

Local name: Budhi maiwa

Family: Rosaceae

Traditional uses: Fruit is carminative. Leaves and fruits are mixed with leaves of Berberis lycium and used in cure of stomach ulcers, also used as antiseptic on the wound externally.

71. Botanical Name: Fumaria indica (Husskin) H. N.

Local name: Papra

Family: Fumariaceae

Traditional uses: It is used as alterative, diuretic, anthelmintic and also used in diabetes. Decoction of whole plant is used in constipation.

72. Botanical Name: Gallium aparine Linn.

Local name: Cochna

Family: Rubiaceae

Traditional uses: Leaves are used in jaundice. The plant is also used traditionally to treat skin diseases.

73. Botanical Name: Gentianodes pedicellata D. Don.

Local name: Nilkant

Family: Gentianaceae

Traditional uses: Decoction of root is used for urinary tract infections, also used for stomachic.

74. Botanical Name: Geranium wallichianum D.Don. 
Local name: Ratanjot

Family: Geraniaceae

Traditional uses: The plant has astringent properties. A paste of the plant is used as a poultice to relieve joint pains. Powdered root is mixed with sugar and milk and used in backache and is also used in strengthening of the body muscles and bones.

75. Botanical Name: Grewia optiva Drum. ex Burret.

Local name: Pastawonay

Family: Tiliaceae

Traditional uses: Leaves and young shoots are fed to cattle, sheep and goats for increasing milk yield and also used as astringent.

76. Botanical Name: Gymnosporia royleana Wall.ex

Lawson.

Local name: Sorazghay

Family: Celastraceae

Traditional uses: The fruit is placed in mouth to relive toothache.

77. Botanical Name: Hedra nepalensis K. Koch.

Local name: Albomor

Family: Araliaceae

Traditional uses: The leaves and berries are said to be cathartic, diaphoretic and stimulant. A decoction of the plant is used to treat skin disease. Leaves are used in diabetes. Juice of the leaves is used for the removal of leeches from the nose of livestock.

78. Botanical Name: Heliotropium cabulicum Bunge.

Local name: Geshay

Family: Boraginaceae

Traditional uses: Whole plant is applied on boils and swellings.

79. Botanical Name: Hypericum perforatum Linn.

Local name: Shenchai

Family: Guttiferae

Traditional uses: Decoction is used in cold and in cough. It is also used as carminative and stimulant.

80. Botanical Name: Impatiens bicolor Royle.

Local name: Bantil

Family: Balsaminaceae

Traditional uses: The fruits are used as diuretic, tonic and cooling effect.

81. Botanical Name: Indigofera hetarentha Wall. ex

Brand.

Local name: Ghoreja

Family: Papilionaceae

Traditional uses: Powdered roots are used as remedy for headache and chest pain.

82. Botanical Name: Inula royleana D.C.

Local name: Kut

Family: Asteraceae

Traditional uses: Plant is considered to be poisonous. Roots are used to control high blood pressure.

83. Botanical Name: Isodon rugosus Linn.

Local name: Sperkay

Family: Labiatae

Traditional uses: The dried leaves are considered useful for toothache.

84. Botanical Name: Jasminum humile Linn.

Local name: Konkoni

Family: Oleaceae

Traditional uses: A paste made from the flowers is considered effective in the treatment of intestinal problems. The juice of the root is used in the treatment of ringworm.

85. Botanical Name: Jasminum officinale Linn.

Local name: Chamba

Family: Oleaceae

Traditional uses: The leaf juice is applied to corns and ear discharges. The leaves are used as an analgesic and febrifuge. The root is used in the treatment of ringworm. The flowers are aphrodisiac, antiseptic, antispasmodic, galactogogue and tonic. Decoction of leaves and flowers are given to infants during fever and as blood purifier. It is also given to livestock during cough and fever and also to increase milk production.

86. Botanical Name: Juglans regia Linn.

Local name: Ghuz

Family: Juglandaceae

Traditional uses: The leaves of the tree are considered to be anti-inflammatory, anthelmintic, alterative, depurative, astringent and also used in cure of various skin diseases. A broth is prepared from the male inflorescence and used for cure of vertigo and coughs. The roots and bark have astringent, anthelmintic and detergent properties. The fruit is also used to cure rheumatism. Bark is finely powdered and used to prevent bleeding gums and as a mouth rinse.

87. Botanical Name: Juniperus communis Brand.

Local name: Gogar

Family: Cupressaceae

Traditional uses: The smoke of leaves is used to cures the effect evil eyes. The oil obtained from berries are used as diuretic, antiseptic, aromatic, stomachic, antirheumatic, cystitis, flatulence, blood tonic and colic.

88. Botanical Name: Justicia adhatoda Linn.

Local name: Baiker

Family: Acanthaceae

Traditional uses: The roots and leaves either in the form of decoction and powder is used in asthma, bronchitis, cough, rheumatism, antispasmodic and expectorant.

89. Botanical Name: Lathyrus aphaca Linn.

Local name: Kokorbang

Family: Papilionaceae

Traditional uses: Ripe seeds are narcotic, also used for wound healing. Dried roots are mixed with wheat flour is administrated orally to livestock for various body infections.

90. Botanical Name: Launea procumbens Roxb.

Local name: Shauda pai

Family: Asteraceae

Traditional uses: Powdered made from the leaves is mixed with sugar and used to enhance lactation.

91. Botanical Name: Lepidium sativum L.

Local name: Alum

Family: Brassicaceae 
Traditional uses: Ten to fifteen dried fruits of the plant are mixed in one glass of milk and butter, boiled, partly cooled and is taken two times a day for two to five days for cholera and abdominal pain.

92. Botanical Name: Mallotus philippensis (Lam) Muell.

Local name: Kambela

Family: Euphorbiaceae

Traditional uses: Glands and hairs on the fruits are used as anthelmintic. Bark is astringent and diuretic. Leaves are bitter, cooling and appetizer.

93. Botanical Name: Malva neglecta Wall.

Local name: Banerak

Family: Malvaceae

Traditional uses: The roots are boiled and mixed with the seeds of Lepidium sativum and used as purgative for young cattle. The leaves and flowers are used as demulcent, as a poultice for bruise, inflammations, insect bites etc, or taken internally in the treatment of respiratory system diseases or inflammation of the digestive or urinary systems.

94. Botanical Name: Marrubium vulgare Linn.

Local name: Kharboti

Family: Labiatae

Traditional uses: Decoction is made from the young leaves and is used against cough. Sugar is added for enhancing flavor.

95. Botanical Name: Melia azedarach Linn.

Local name: Bikyana

Family: Meliaceae

Traditional uses: Decoction of leaves is used in hysteria. Seeds are used in rheumatism and hypertension.

96. Botanical Name: Mentha longifolia (L.) Huds.

Local name: Villanay

Family: Labiatae

Traditional uses: Powdered leaves are used as carminative, in diarrhea, dysentery and stomachache. The plant is also used for its antiseptic properties and its beneficial effect on the digestion. The leaves and flowering stems are antispasmodic, carminative and stimulant. A tea made from the leaves has traditionally been used in the treatment of fevers, headaches, digestive disorders and various minor ailments.

97. Botanical Name: Mentha spicata Linn.

Local name: Podina

Family: Labiatae

Traditional uses: It is carminative and is used in diarrhea, dysentery and stomachache. Leaves are used for salad, spice etc.

98. Botanical Name: Micromeria biflora (Buchi. Ham. ex D. Don) Benth.

Local name: Yakha booti

Family: Labiatae

Traditional uses: A paste of the root is pressed between the jaws to treat toothache. The plant is rubbed and the aroma inhaled to treat nose bleeds. A paste of the plant is used as a poultice to treat wounds. The juice of the plant is taken internally and also inhaled in the treatment of sinusitis. The stem and the leaves of the plant are plucked, chewed and the juice is swallowed to relive abdominal pain.

99. Botanical Name: Mirabalis jalpa Linn.

Local name: Gule badam

Family: Nyctaginaceae

Traditional uses: A hot poultice of leaves is used to mature and resolve boils. Leaf juice is used for cleaning and healing wounds. A paste of the root is applied as a poultice to treat scabies and muscular swellings. The powdered root, mixed with corn flour (Zea mays) is baked and used in the treatment of menstrual disorders.

100. Botanical Name: Momordica charantia L..

Local name: Karela

Family: Cucurbetaceae

Traditional uses: Fruit juice is used for the treatment of diabetes also used in Jaundice.

101. Botanical Name: Morchella spp. Linn.

Local name: Gochai

Family: Helvelaceae

Traditional uses: Whole plant is used as general body tonic.

102. Botanical Name: Morus alba Linn.

Local name: Spin toot

Family: Moraceae

Traditional uses: The leaf extract are used against snake bite, edema, hemorrhage and myonecrotic. The bark is used to treat cough, wheezing, edema, promote urination, fever, and headache, red dry and sore eyes.

103. Botanical Name: Morus nigra Linn.

Local name: Tor toot

Family: Moraceae

Traditional uses: Fruit are laxative, cooling and aromatic. Leaves decoction is used for cleaning throat. Root is anthelmintic and astringent.

104. Botanical Name: Myrsine africana $\mathrm{L}$.

Local name: Mangaya / Maru rang

Family: Myrsinaceae

Traditional uses: The powdered fruit is used as anthelmintic, especially in the treatment of tape worm. A decoction of the leaves is used as blood purifier. The powdered fruit is mixed and is used in the treatment of cough.

105. Botanical Name: Myrtus communis Linn.

Local name: Manoo

Family: Myrtaceae

Traditional uses: Leaves are boiled in water with sugar (ghur), and its decoction is used for abdominal pain and diarrhea. The plant is taken internally in the treatment of urinary infections, digestive problems, vaginal discharge, bronchial congestion, sinusitis and dry coughs.

106. Botanical Name: Narcissus tazetta Linn.

Local name: Gul-e-Nargis

Family: Amaryllidaceae

Traditional uses: It is used in the treatment of boils and mastitis. The root is emetic. It is used to relieve headaches. The root is applied as poultice to abscesses, boils and other skin complaints.

107. Botanical Name: Nerium indicum Mill.

Local name: Ganderay 
Family: Apocynaceae

Traditional uses: Every part of the plant is poisonous. The whole plant is used with care. The decoction of the flowers is used as a general insecticide to kill lice and other insects. The powdered bark, mixed with castor oil, can be applied over skin eruptions. The leaves and bark are used for snake bites and as an insecticide.

108. Botanical Name: Olea ferrugenea Ryole.

Local name: Khona

Family: Oleaceae

Traditional uses: Leaves are astringent, antiseptic and diuretic. Locally the leaves are used in soar throat and toothache.

109. Botanical Name: Onosma echioides

Family: Boraginaceae

Traditional uses: The leaves are alterative. The powder of plant is given to children as purgative. The flowers are used as a cordial and stimulant in the treatment of rheumatism and palpitations of the heart. The root is used to threat skin eruptions.

110. Botanical Name: Opuntia dilleni Haw.

Local Name: Zaqoom

Family: Cactaceae

Traditional uses: Phylloclade's poultice is used for extracting guinea worms. Fruits are edible, demulcent and expectorant. The ripe fruits juice is useful remedy for asthma and whooping cough.

111. Botanical Name: Origanum vulgare Linn.

Local name: Ishpain

Family: Labiatae

Traditional uses: Shoot is chewed for toothache. It is also used as flavoring agent.

112. Botanical Name: Otostegia limbata (Benth.) Boiss.

Local name: Pishkand

Family: Labiatae

Traditional uses: Dried powdered plant is used in jaundice. An aqueous extract of the herb is locally used for treatment of eye inflammations and infections. The plant is also used as remedy for hypertension.

113. Botanical Name: Oxalis corniculata Linn.

Local name: Zmakay tarookay

Family: Oxalidaceae

Traditional uses: Leaves are anti ascorbic, cooling and used in stomach disorder. The plant is mixed with maize flour and used for diarrhea treatment in livestock.

114. Botanical Name: Paeonia emodi Wall. ex Hook. f.

Local name: Mamekh

Family: Paeoniaceae

Traditional uses: The infusion of dried flower is used in diarrhea. Rhizome is used to increase milk production in livestock, also used as tonic.

115. Botanical Name: Persicaria stagnina Buch - Ham. ex Meisn.

Local name: Pulpulak

Family: Polygonaceae

Traditional uses: Root is cooling and astringent. Seed is used in colic. The plant is also locally used for killing fish- es.

116. Botanical Name: Pinus roxburghii Sargent.

Local name: Nakhtar

Family: Pinaceae

Traditional uses: Resin of bark (jaula) is stimulant used in ulcer, skin diseases, snakebites and scorpion stings. It is used for treatment of skin complaints, wounds, sores, burns and boils.

117. Botanical Name: Pistacea integerrima J. L. Stewart.

Local name: Shnai

Family: Anacardaceae

Traditional uses: Fruits and galls extract are used as tonic and expectorant. The plant is used in the treatment of coughs, phthisis, asthma and dysentery. The decoction of leaves is used for body cooling and hepatitis.

118. Botanical Name: Plantago lanceolata Linn.

Local name: Chamchi patar

Family: Plantaginaceae

Traditional uses: Powdered leaves are used as antiseptic. The paste of leaves is used for all types of sores on the skin, cuts, bites and various inflammations. Decoction of seeds is used for the treatment of diarrhoea and dysentery and for bleeding in the mouth or other mucous membranes.

119. Botanical Name: Plantago major Aitch.

Local name: Jabai

Family: Plantaginaceae

Traditional uses: It is used as astringent, tonic, stimulant, antiseptic, also used in stomach disorders, in fever and dysentery. A decoction of the roots is used in the treatment of diarrhea, dysentery, gastritis, bronchitis, catarrh, sinusitis, coughs, asthma and hay fever.

120. Botanical Name: Platanus orientalis Linn.

Local name: Chinar

Family: Plantanaceae

Traditional uses: Bark is useful remedy in diarrhea and dysentery. Fresh leaves bruised and applied to the eye in ophthalmic diseases.

121. Botanical Name: Podophyllum emodi Wall. ex Royle.

Local name: Bankakri

Family: Podophyllaceae

Traditional uses: Rhizome and root are hepatic stimulant, purgative and emetic. Flower is used for fever and body pain. Rhizome is given to cattle for fever and milk production.

122. Botanical Name: Poligonatum verticelatum (Linn.) All.

Local name: Norealam

Family: Liliaceae

Traditional uses: Rhizome is mixed with sugar and used for treatment of joint pain, also used as aphrodisiac. The decoction of dried rhizome is administrated to livestock for removal of placenta.

123. Botanical Name: Polygonum amplexicaule D. Don.

Local name: Masloon

Family: Polygonaceae

Traditional uses: Rhizome is crushed and mixed with milk to soften mammary gland of livestock and also given 
in diarrhea.

124. Botanical Name: Populus alba Linn.

Local name: Bensa, Aspai and Shafeda

Family: Salicaceae

Traditional uses: The juice of fresh leaves is given to livestock for Mouth and Foot diseases. The branches are supposed to control diseases of rice crop.

125. Botanical Name: Portulaca oleracea Linn.

Local name: Warkhary

Family: Portulaceae

Traditional uses: It is used as a remedy for constipation and inflammation of the urinary system. Whole plant is mixed with Chenopodium and used in treatments for internal parasites. The fresh herb is applied topically to relieve sores and insect or snake bites on the skin.

126. Botanical Name: Primula denticulata Smith.

Local name: Asal Mamera

Family: Primulaceae

Traditional uses: Flowers are used as ophthalmic and as hair tonic.

127. Botanical Name: Prunus domestica L.

Local name: Alucha

Family: Rosaceae

Traditional uses: It is used as laxative and flavoring agent. Fruit pulp is used in chutneys.

128. Botanical Name: Prunus padus Hook.f.

Local name: Barith

Family: Rosaceae

Traditional uses: Fruits is used as narcotic. The bark is mildly anodyne, diuretic, febrifuge and sedative. An infusion is used in the treatment of colds.

129.Botanical name: Prunus persica (L.) Batsch

Local name: Shalthalo

Family: Rosaceae

Traditional uses: The dried fruits and ginger are crushed into powder. This powder is mixed with honey and eaten for body cooling and diabetes. The resin is boiled in water, cool down and used for earache and deafness.

130.Botanical Name: Pteris cretica Linn.

Local name: Qinchi panra

Family: Pteridaceae

Traditional uses: The whole plant is given to livestock during cough.

131. Botanical Name: Punica granatum Linn.

Local name: Narsaway

Family: Punicaceae

Traditional uses: A decoction of seed is used to treat syphilis. Its juice of seeds is used to treat jaundice and diarrhea. Juice of the fruit is used to treat jaundice and diarrhea. The rind of the fruit is ground in water and drunk every morning by diabetics. The fruit together with the juice of Cynodon dactylon leaves is used for runny noses and colds. The juice of the flowers is used to treat nose bleeds. The fruit pulp and the seed are a stomachic. The root and stem bark have astringent and anthelmintic properties.

132. Botanical Name: Pyrus pashia Buch.-Ham.ex D.Don.

Local name: Tangai
Family: Rosaceae

Traditional uses: Juice of fruits is used for eyes infections in livestock. The juice of the ripe fruit is used in the treatment of diarrhea.

133. Botanical Name: Quercus dilatata Lindle. ex Royle.

Local name: Tor banj

Family: Fagaceae

Traditional uses: Powdered fruit are used to treat gonorrhea and urinary diseases. It is also astringent and diuretic, used in diarrhea, indigestion and asthma.

134. Botanical Name: Quercus incana Roxb.

Local name: Spin banj

Family: Fagaceae

Traditional uses: Fruits is used as astringent, diuretic, diarrhea and asthma.

135. Botanical Name: Rhododendron arboreum Smith.

Local name: Gulamair

Family: Ericaceae

Traditional uses: Leaves paste is applied to the forehead in the treatment of headaches. The juice of the bark is used in the treatment of coughs, diarrhoea and dysentery and Diabetes, piles, Jaundice, liver disorder and worms. It is also used in skin diseases. Flower petals are used as tonic.

136. Botanical Name: Rhus javanica Linn.

Local name: Tetray

Family: Anacardiaceae

Traditional uses: The fruits are carminative and are recommended in colic.

137. Botanical Name: Ricinus communis Linn.

Local name: Arind

Family: Euphorbiaceae

Traditional uses: Leaves are emetic, narcotic and purgative. Leaves poultice is applied to swellings. Seed oil is purgative.

138. Botanical Name: Rosa moschata J. Herm.

Local name: Qurach

Family: Rosaceae

Traditional uses: Decoction of flowers is used in stomach disorder. The fruit is used for the treatment of cancer. The leaves and flowers are used in the treatment of bilious affections, burning of the skin and eye diseases.

139. Botanical Name: Rubus ellipticus Smith.

Local name: Goraj

Family: Rosaceae

Traditional uses: The juice and decoction of the root is used in the treatment of fever, gastric troubles, diarrhea and dysentery. A paste of the roots is applied externally to wounds. Both the root and young leaves are used in colic. The juice of the fruit is used in the treatment of fever, colic, cough and sore throat.

140. Botanical Name: Rubus fructicosus Hook .f.

Local name: Baganra

Family: Rosaceae

Traditional uses: Leaves are used for the treatment of diarrhea, cough and fever. Fruit are used as carminative. The chewing of the leaves is used for bleeding gums. The fruit and juice are taken for anemia. The decoction or powder of 
the root is good to break or drive forth gravel and the stone in the reins and kidneys.

141. Botanical Name: Rubus ulmifolius Schott.

Local name: Karwara

Family: Rosaceae

Traditional uses: Fruits are edible and carminative. Unripe fruit are used as tonic and aphrodisiac. Roots and leaves are used for the treatment $\mathrm{f}$ skin diseases.

142. Botanical Name: Rumex dentatus Linn.

Local name: Shalkhay

Family: Polygonaceae

Traditional uses: The root is used as astringent. Fresh leaves mixed with wheat flour and are used for treatment of constipation in livestock. Young leaves are cooked as vegetable.

143. Botanical Name: Rumex hastatus D. Don.

Local name: Tarukay

Family: Polygonaceae

Traditional uses: It is used as carminative, purgative, astringent and diuretic. Root is used in jaundice. It is also used as antiseptic.

144. Botanical Name: Rumex nepalansis Spreng.

Local name: Shalkhay

Family: Polygonaceae

Traditional uses: Whole plant is used as diuretic, astringent, purgative and demulcent. The root is purgative. A strong decoction of the root is applied to dislocated bones. A paste of the root is applied to swollen gums. The leaves are used in the treatment of colic. The juice of the leaves is applied externally to relieve headaches.

145. Botanical Name: Salix babilonica Linn.

Local name: Asela ola

Family: Salicaceae

Traditional uses: A decoction of the leaves is used in the treatment of abscesses, carbuncle, fever, rheumatism and skin diseases. An infusion of the bark has been used to treat diarrhea and fevers. The bark can be used as a poultice. Powdered leaves are also used in diabetics.

146. Botanical Name: Sarcococca saligna (D. Don.) Muell.

Local name: Bansatra

Family: Buxaceae

Traditional uses: Bark of the root is antiseptic and also used as blood purifier. Leaves and shoots are boiled and applied on swollen joints in the form of poultice. The leaves are heated in mustered oil and applied to muscular pain.

147. Botanical Name: Saussurea sp.

Local name: Kut

Family: Asteraceae

Traditional uses: Powder root is used as tonic, stimulant, carminative, chronic ulcer, also used in asthma and cough.

148. Botanical Name: Silene conoidea L.

Local name: Mashroa

Family: Caryophyllaceae

Traditional uses: A paste is prepared by grinding seeds and young leaves which is applied on pimples. This paste is also used for backache.

149. Botanical Name: Silene vulgaris (Moench) Garcke.
Local name: Mashroa

Family: Caryophyllaceae

Traditional uses: Shoots are used as stomachic and emollient.

150. Botanical Name: Silybum marianum Gaertn.

Local name: Rejakai

Family: Asteraceae

Traditional uses: Infusion of leaves is used in throat and chest infections. Seeds are expectorant and stimulant. It is also used in cases of liver and gallbladder disease.

151. Botanical Name: Skimmia laureola DC.

Local name: Ner

Family: Rutaceae

Traditional uses: Smoke of burned leaves is used in cleaning the nasal tract also used in cough and cold.

152. Botanical Name: Solanum nigrum L.

Local name: Kachmachu

Family: Solanaceae

Traditional uses: Fruit is edible. The boiled extracts of leaves and berries are also used to alleviate the patient's discomfort in liver-related ailments including jaundice.

153. Botanical Name: Solanum surratense Burm.f.

Local name: Maraghonay

Family: Solanaceae

Traditional uses: Fruits are used in jaundice. A paste of the root can be prepared by grinding with lemon juice and applying to the affected parts by snake and scorpion bites.

154. Botanical Name: Solena amplexicaulis (Lam.) Gandhi

Local name: Kakora and Bankakra

Family: Cucurbitaceae

Traditional uses: The rhizome is crushed and mixed with maize flour and given to livestock for promotion milk production and for fever. The root and seeds are considered stimulant and purgative.

155. Botanical Name: Stellaria media (L.) Cyr.

Local name: Larolay

Family: Caryophyllaceae

Traditional uses: It is used as a poultice or ointment for skin irritations, skin abscesses and boils. It is used in rheumatism, joint diseases and constipation.

156. Botanical Name: Swertia paniculata Wall.

Local name: Momera

Family: Gentianaceae

Traditional uses: Decoction of the plant is used as tonic. Plant is also used in the treatment of malaria and other fever. The ripe shoots have powder-like substance, which is used for curing eye diseases.

157. Botanical Name: Taraxacum officinale Weber.

Local name: Hind

Family: Asteraceae

Traditional uses: The root is used in diabetics, jaundice, kidney disorders and as diuretic. A leaf decoction are used to "purify the blood", for the treatment of anemia, jaundice, and also for nervousness. The milky latex has been used as a mosquito repellent.

158. Botanical Name: Taxus wallichiana Zuce.

Local name: Barmi 
Family: Taxaceae

Traditional uses: Bark is used in cancer and pneumonia. Leaves are used in bronchitis, whooping cough and asthma. The plant is highly toxic and occasionally used medicinally. Externally, the leaves have been used in a steam bath as a treatment for rheumatism.

159. Botanical Name: Thymus linearis Benth.

Local name: Jaman

Family: Labiatae

Traditional uses: Decoction of leaves is used for fever, cough and cold. Seeds are used for abdominal pain. Juice from leaves is applied to toothache.

160.Botanical name: Tribulus terrestris L.

Local name: Marondai

Family: Zygophyllaceae

Traditional uses: Powder fruit is mixed in water and used in case of body pain.

161. Botanical Name: Urtica dioica Linn.

Local name: Jalbang

Family: Urticaceae

Traditional uses: Juice of the plant is external irritant. Leaves are mixed with fodder are fed to livestock to increase milk production. The juice of the roots or leaves, mixed with honey or sugar relieve bronchial and asthmatic troubles, and the dried leaves, burnt and inhaled will have the same effect.

162. Botanical Name: Valeriana jatamansi Jones.

Local name: Mushkbala

Family: Valerianaceae

Traditional uses: Whole plant is fed to livestock to promote milk production. The juice of the whole plant is used as hair tonic.

163. Botanical Name: Verbascum thapsus Linn.

Local name: Khardag

Family: Scrophulariaceae

Traditional uses: The decoction of leaves and flowers are used in cough, pulmonary diseases, bleeding of bowels and other skin diseases.

164. Botanical Name: Verbena officinalis Linn.

Local name: Shamkay

Family: Verbenaceae

Traditional uses: It is used in rheumatism and joint diseases. Root is antidote to snakebite.

165. Botanical Name: Vibernum cotonifolium D.Don.

Local name: Bring

Family: Caprifoliaceae

Traditional uses: Fruits is used as general body tonic.

166. Botanical Name: Viola canescens Wall .ex Roxb.

Local name: Banafsha

Family: Violaceae

Traditional uses: Flower and leaves are used in cough, cold and fever. Whole plant is used in jaundice.

167. Botanical Name: Vitex negundo Linn.

Local name: Marvanday

Family: Verbenaceae

Traditional uses: The leaves are applied to rheumatic swellings of the joints and in sprains. The juice of the leaves is used for the treatment of fetid discharges. The essential oil is used to reduce inflammation and swelling of joints due to rheumatism and injuries. Fresh roots are used as bandage to relive pain of chest and back. Branches are used as miswak. Leaves are smoked to relive headache.

168. Botanical Name: Withania somnifera (Linn.) Dunal.

Local name: Asghand

Family: Solanaceae

Traditional uses: Leaves and roots are used as poultice on swellings. Fruits and seeds are used as diuretic. Vegetable made out of this plant is given to TB patients.

169. Botanical Name: Xanthium stromarium Linn.

Local name: Desi Arind

Family: Asteraceae

Traditional uses: Fruit is demulcent and cooling, used in small pox. Leaves decoction is recommended in long standing malarial fever. An infusion of the plant has been used in the treatment of rheumatism, diseased kidneys and tuberculosis. A decoction of the root has been used in the treatment of high fevers and to help a woman expel the afterbirth. A decoction of the seeds has been used in the treatment of bladder complaints. A poultice of the powdered seed has been applied as a salve on open sores.

170. Botanical Name: Zanthoxylum armatum D. C.

Local name: Dambara

Family: Rutaceae

Traditional uses: Seed and bark are tonic and aromatic and are used in fever, cholera and dyspepsia. Fruit is used to cure stomachache and toothache.

171. Botanical Name: Zizyphus oxyphylla Edgew.

Local name: Elanai

Family: Rhamnaceae

Traditional uses: Various parts are traditionally used as remedy of pain, diabetes, allergy, fever, rheumatic, pain. The roots and fruits are used in jaundice and gas trouble, leaves extract are used as antipyretic.

172. Botanical Name: Zizyphus vulgare Lam.

Local name: Markhanai

Family: Rhamnaceae

Traditional uses: All parts of the plant are used in diabetics.

\section{Discussions}

The present day ethno-botanical pharmacology is as old as man himself[4] and the medicinal plants have been in use from the time immemorial[16]. Rig Veda between 45001600 BC and Ayurveda between 2500-600 BC are considered among the first compiled records of medicinal plants in Indo-Pak[17].

The prevalent system of traditional medicine traces its origin to Greek medicine system, which was adopted by the Arabs, and spread to the subcontinent and Europe[18]. Whereas, Susruta Samhita (600 BC), a Sanskrit text on surgery, mentioned the progress made during Buddhist period, where medicinal plants were cultivated by qualified specialists[17]. 
In developed countries people still rely on traditional system of healthcare not only because of its low price, but also due to very less side effects, as compared to the modern allopathic medicines[19]. That is why they are being used extensively world over especially in the third world countries.

The people of the Allai valley have been using plant resources for their various ailments. The local people know the useful plants and preparation of recipes through personal experience and ancestral prescription and long utility. People of the valley collect plants for medicinal uses, fuel, fodder, timber, and many other purposes[8].

During present study a total of 172 medicinal plants were studied including 24 ethno-veterinary important plants. Majority of the recipes are prepared in the form of decoction from freshly collected plant parts. Mostly a single species were used and mainly taken orally. They used medicinal plants for asthma, cough, tonic, abdominal pain, expectorant, anthelmintic, carminative, on boils, snakebites, jaundice, diarrhea and dysentery etc. Local people take the recipes in powder form, in paste form, decoction, infusion or plant juice etc and usually taken 2-3 time a day for 3-15 days depends on the nature of disease and recipes. Some of the medicinal plant species were extensively exploited by the local people for their various ethno-botanical uses.

Field observation showed that vegetation of the area was generally threatened with the unwise of local communities. The trends like urbanization, deforestation, over grazing, habitat fragmentation, unscientific extraction of natural vegetation, introduction of the exotic taxa and habitat loss were the visible threats.

It is recommended that the local community should be educated regarding the importance, pre and post harvest methods. In addition, they should also be trained regarding the cultivation of these highly valuable medicinal plants on commercial basis, and thereafter their trade and marketing. This will ultimately generate extra sources of income and will reduce pressure on the extraction of these valuable medicinal plants.

In Allai valley the use of plant resources is also a source of income, besides fulfilling their various utilitarian needs. Settlements of majority of the population are subject to the seasonal changes in the valley. In winter they come down to the valley bottoms due to the unavailability of fodder for their cattle, and at the onset of summer as the snow melts and new plants start sprouting, they move towards the higher altitudes.

The local people are ignorant about the importance of these plants at global level. Sometimes they collect plants in excess quantity and in most cases the whole plant is uprooted. They do not know about the proper methods and time of plant collection, as a result most of their collection is useless. On the other hand they are ignorant about the drying, storing or preserving techniques, which ultimately lead to wastage of plant resource.

\section{REFERENCES}

[1] F. Haq, H. Ahmad and M. Alam (2011). Traditional uses of medicinal plants of Nandiar Khuwarr catchment (District Battagram), Pakistan. Journal of Medicinal Plants Research Vol. 5(1), pp. 39-48

[2] H. Ali, H. Ahmad and M. Yousaf (2003). Trade of local medicinal herbs in Mingora City. In: Proceedings of Workshop on Conservation and sustainable uses of Medicinal and Aromatic plants of Pakistan. (Eds.): H. Ahmad, A. A. Khan

[3] R. Qureshi, G. R. Bhatti, R. A. Memon (2010). Ethnomedicinal uses of Herbs from Northern part of Nara Desert, Pakistan. Pak. J. Bot., 42(2): 839-851

[4] H. Ali, M. Qaiser (2009). The Ethno botany of Chitral valley, Pakistan with Particular reference to medicinal plants. Pak. J. Bot., 41(4): 2009-2041

[5] C. S. Olsen, N. K. Bhattarai (2005). A typology of economic agents in the Himalayan plant trade. Mountain Res. Dev., 25: $37-43$

[6] N. R. Fransworth, D. D. Soejarto (1991). Global importance of medicinal plants. In: O., Akerele, V. Heywood and H. Synge, (Eds.): The conservation of medicinal plants: proceedings of an international consultation 21-27 March 1988, Chiang Mai, Thailand Cambridge University Press, Cambridge, pp. 25-51

[7] A. Titz (2004). Medicinal herbs and plants scope for diversified and sustainable extraction. 22- 26 July 2004

[8] F. Haq, H. Ahmad, M. Alam, I. Ahmad and Rahatullah (2010). Species diversity of vascular plants of Allai valley western Himalaya, Pakistan. Pak. J. Bot., Special Issue (S.I. Ali Festschrift) 42: 213-229, 2010

[9] F. Haq (2011). Conservation status of the critically endangered and endangered species in the Nandiar Khuwar catchment District Battagram, Pakistan. International Journal of Biodiversity and Conservation Vol. 3(2), pp. 27-35

[10] S. Muhammad (2004). Resource Management Plan Allai forests

[11] Ahsan N, Chaudhry MN, Gondal MMI, Khan ZK (2009). Allai aggregate for Rehibilitation and Reconstruction of October 8, 2005 Earthquake affected Allai-Banan area, NWFP, Pakistan. Geol. Bull. Punjab Univ. 44, 2009

[12] F. J. Lipp (1989). Methods for ethnopharmacological fieldwork. J. Ethnopharmacol., 25: 1939-150

[13] E. Nasir and S. I. Ali (1970-89). Flora of Pakistan. No. 1-190. National Herbarium, PARC, Islamabad and Department of Botany, University of Karachi, Pakistan

[14] S. I. Ali and Y. J. Nasir (1990-92). Flora of Pakistan. No. 191-193. Department of Botany, University of Karachi and National Herbarium, PARC, Islamabad

[15] S. I. Ali and M. Qaisar (1992-2007). Flora of Pakistan. Nos. 194-208. Department of Botany, University of Karachi and National Herbarium, PARC, Islamabad

[16] M. Pärtel, R. Kalamees, Ü. Reier, E. Tuvi, E. Roosaluste, A. Vellak, M. Zobel (2005). Grouping and prioritization of vascular plant species for conservation: combining natural rarity and management need. Biol. Cons., 123: 271-278 
[17] H. Ahmad (2003). Mankial valley: an introduction to the medicinal flor $a$. Wildlife Department Swat, GIF and MBCP Swat, pp. 28-33

[18] I. Iqbal, M. Hamayun (2004). Studies on the traditional uses of plants of Malam Jabba valley, District Swat, Pakistan. J. Ethnobot. Leaflets
[19] A. A. Khan (2003). Role of conservation of medicinal and aromatic plants in the socioeconomic development of rural poor's. International Workshop on conservation and sustainable uses of medicinal and aromatic plants in Pakistan. Joint venture by WWF-P, MINFAL and Qarshi Industries Pvt. Ltd 